\title{
ELECTROKINETIC PHENOMENA
}

XII. Electroosmotic and Electrophoretic Mobilities of Protein SuRfaces in Dilute Salt Solutions

By LAURENCE S. MOYER* aND HAROLD A. ABRAMSON

(From the Biological Laboratory, Cold Spring Harbor, Long Island)

(Accepted for publication, September 11, 1935)

INTRODUCTION

It has been shown by Abramson (1) and confirmed by Daniel (2) that the $\zeta$-potential of inert microscopic particles covered by protein films is the same as that calculated for the $\zeta$-potential of the wall of the electrophoresis cell when coated with the same protein. These measurements had usually, though not always, been made in the presence of considerable concentrations of electrolytes. The significance of these results may also be stated as indicating that the ratio of the electroosmotic mobility, $u$, to the electrophoretic mobility, $v$, was found to be 1.0 , so that,

$$
R=\frac{u}{v}=1.0,
$$

very nearly, taking the same sign as the $\zeta$-potential.

White, Monaghan, and Urban (3) have recently contended that the value of $R$ for protein-covered surfaces is equal to 1.0 only when the electrolyte concentration is greater than $0.01 \mathrm{~m}$. They found that, with their technic, ratios up to 2.3 were obtained in very dilute salt solutions and distilled water. Contrary to these observations are the experiments of Bull (4). Bull compared the $\zeta$-potential calculated not only from electrophoresis and electroosmosis experiments but also from streaming potential measurements. Bull found that protein-covered surfaces in dilutions as great as $3.5 \times 10^{-4} \mathrm{~N}$ yielded a value of $R$ equal to 1.0 within the limit of error, for $\zeta$ de-

* Sterling Fellow; Yale University, 1935-36. 
termined by electrophoresis, electroosmosis, and the streaming potential technics. White, Monaghan, and Urban's comparable figure lies between $R=1.31$ and $R=1.57$.

In this communication, evidence will be presented which indicates that in dilute salt solutions certain protein-coated surfaces exhibit a value of $R$ equal to 1.0, very nearly, thus confirming the experiments of Bull, and contrary to those of White, Monaghan, and Urban.

\section{Methods}

Type of Cell.-A flat electrophoresis cell (5) which has been described in detail as Cell " $B$ " by Abramson and Grossman (6), and which had been checked against another cell, was employed in these investigations. The use of this cell, which is quite rectangular in cross-section, provides a hydrodynamic system which follows closely the theory of von Smoluchowski. It is necessary to clean the cell with particular care between experiments. Since the entire apparatus is of one piece of glass, molar $\mathrm{NaOH}$ could be used to remove the adsorbed protein. This was followed by dilute acid and distilled water.

Calculation of the Field Strength.-The values of the mobilities given in the figures have been calculated as usual from Ohm's law $(7,8)$ and the observed velocities. Due correction was made for fluctuations of current and therefore changes in field strength within the cell. We wish to emphasize that other methods of calculation of the field strength which do not entail the measurement of current may lead to erroneous conclusions. This point is of special importance when comparing results obtained over a wide range of electrolyte concentrations.

The use of plaster of Paris plugs $(6,9)$ at the junction of suspension and electrode vessel prevents convection of the electrolyte from the electrode vessel and diminishes the chance of contamination of the particles under investigation.

Preparation of Suspensions.-Finely powdered, carefully cleaned, quartz particles (9), about $1 \mu$ in diameter, were used to adsorb the proteins investigated. In one experiment, protein-coated pyrex glass particles were simultaneously observed with protein-coated paraffin oil globules. The particles were, as usual (10), suspended 
in concentrated protein solutions (1 per cent) and the suspension then diluted to final concentrations of protein ranging between 0.2 per cent and 0.02 per cent. While the particles were in contact with the protein solution, the electrophoresis cell was filled with a protein solution of the same concentration. The cell itself was finally washed with a large volume of the final dilution of the suspension. Three proteins-Coignet gelatin, Agfa Lichtfilter gelatin, and a highly purified gliadin (Dill)-furnished the surface deposits of adsorbed materials.

The suspensions having the lowest conductances in Table II contained protein which had been dialyzed for several days in an ice box.

Recording of Time.- One of us observed the motion of the particles in the electric field and pressed the stop-watch lever when the particles had traversed a suitable distance, their direction being reversed during the measurement. The other observer recorded the stop-watch readings which were unknown to the observer timing the particles.

\section{EXPERIMENTAL}

\section{Calculation of $v$ and $u$ Assuming $c=0$}

In view of the controversial nature of the problem under discussion, a large number of measurements were made at random at various levels of the electrophoresis cell in each experiment. It can be readily shown that velocity-level curves found in a long and wide cell of rectangular cross-section are given by an expression of the form,

$$
y=b\left(x-x^{2}\right)+c .
$$

Here $y$ is the velocity observed at a distance, $x$, from the ceiling of the cell with a total thickness, $x=1$. The terms $b$ and $c$ are constants. When $R=1.0, c=0$. If $R=1.5$ or $R=2.0$,

$$
y=(v-u)=-c,
$$

with proper regard to sign, at $x=0$ and $x=1$. The sign of $c$ is always negative when $R>1$.

Three to five measurements of $y$ were usually made, in the experiments here reported, at each of the different levels. These values which generally agreed within 10 per cent were averaged and a value of $b$ calculated (Table I) for each set of points at each level investi- 
gated, letting $c=0$. An average value of $b$ was readily obtained from the points, as indicated in the table, and a theoretical curve drawn by means of equation (1), taking the average value of $b$. Values of $b$ from which the theoretical curves were obtained lay between the limits $x=0.1$ and $x=0.9$. Evidently this curve corresponds to the condition that $R=1$, for $u=v$. In addition, when desired, similar curves were drawn for $R=1.5$ and $R=2.0$, based

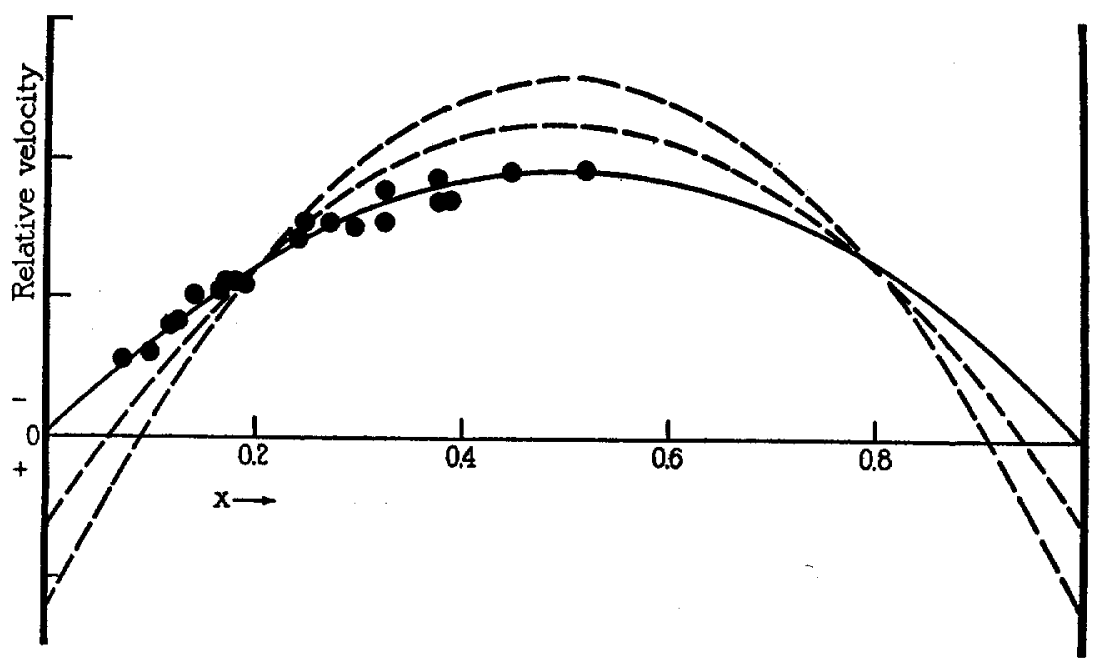

Fig. 1. Experiment with gelatin-coated (Coignet) quartz particles. Ordinate values of $v$ are in relative units plotted against depth, $x$, in the electrophoresis cell. The smooth, unbroken curve (lowest) has been calculated from equation (1), taking $c=0$. The two upper curves (dashed) have been calculated, taking $R=1.5$ and $R=2.0$. It is evident that within the limits of error the experimental points fit the curve for $R=1.0$, indicating that electrophoresis and electroosmosis are equal. See Table II. The velocities given in each figure have been reduced to constant field strength.

upon the value of $v$ obtained at the level $0.2(0.8)$ with appropriate values of $c$. Evidently the value of $v$ must remain the same, independent of the value assigned to $R$. In consequence, curves derived from $v$ held constant but with $u$ varying, must all intersect at the level $0.2(0.8)$. This procedure avoids the errors ${ }^{2}$ or difficulties

${ }^{1}$ It can be easily shown that in the determination of $R$ by the use of Equation 3 an error of 10 per cent in the measurement of $v_{0.5}$ or $v_{0.2(0.8)}$ causes a divergence of about 30 per cent in the value of $R$. 
inherent in using the equations,

$$
u=2\left(v_{0.5}-v_{0.2(0.8)}\right)
$$

and

$$
u=v_{0}-v_{0.2(0.8)},
$$

where the subscripts refer to the cell depth. Our present procedure, rather, takes into consideration a large number of experimental points and includes electric mobilities throughout the entire cell.

The results of our experiments and calculations are presented in Figs. 1-7 and in Tables I and II. Every point, rather than averages

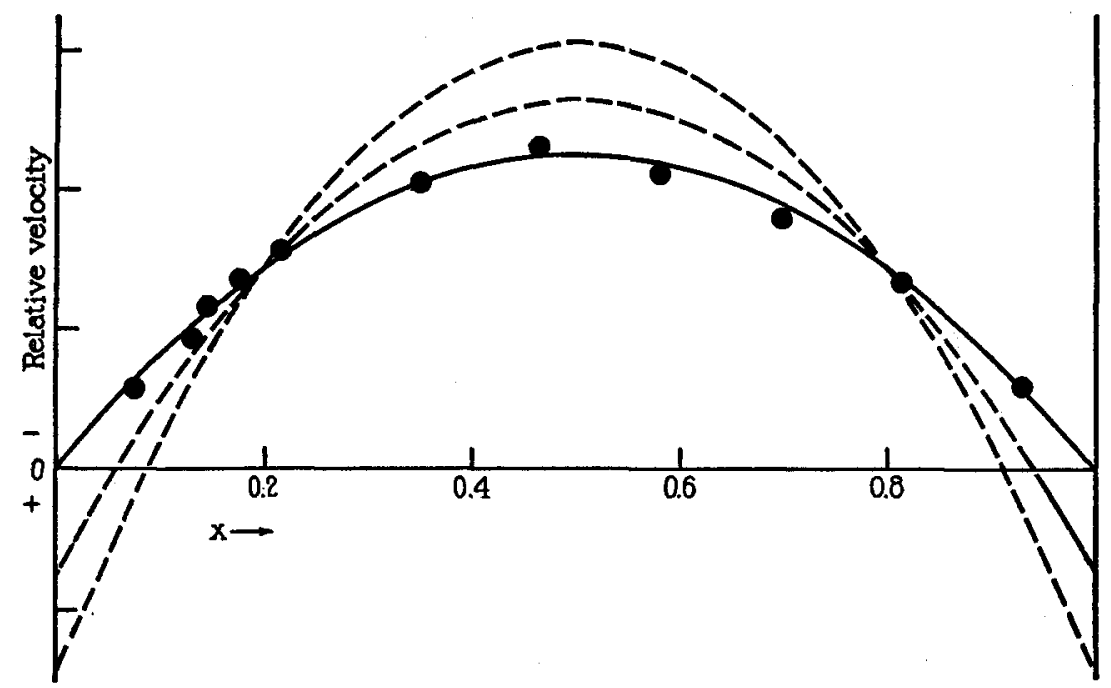

Fig. 2. Similar to Fig. 1, except that each point is an average of several measurements at the levels indicated. See Table II.

.at a given level, is plotted in Figs. 1 and 5. Note in the figures that the experimental values in every case fit the theoretical curve drawn on the assumption that $c=0$. This agreement demonstrates that under our conditions the electrophoretic mobility of particles coated with gelatin (and, in one experiment, with gliadin ${ }^{2}$ ) is practically equal

2 Our results with gelatin and with gliadin do not appear to be in accord with experiments of Kemp and Rideal (11). These investigators reported that the mobility of gliadin-coated particles of different radii is dependent upon their radii in dilute solutions. 
to the electroosmotic mobility even in the most dilute solutions. The value of $R$, in accord with these experiments, is, therefore, very close to 1.0. Certainly there is no indication that the data fit the dashed curves drawn so that $R=1.5$ or $R=2.0$. Occasionally, very slight movement in the reverse direction was noted at the floor of the cell (discussed in more detail below) as depicted in Figs. 3, 4, 5 , and 7. The velocity in the reverse direction was, however, very small and when this reversal was observed, the reversal occurs very

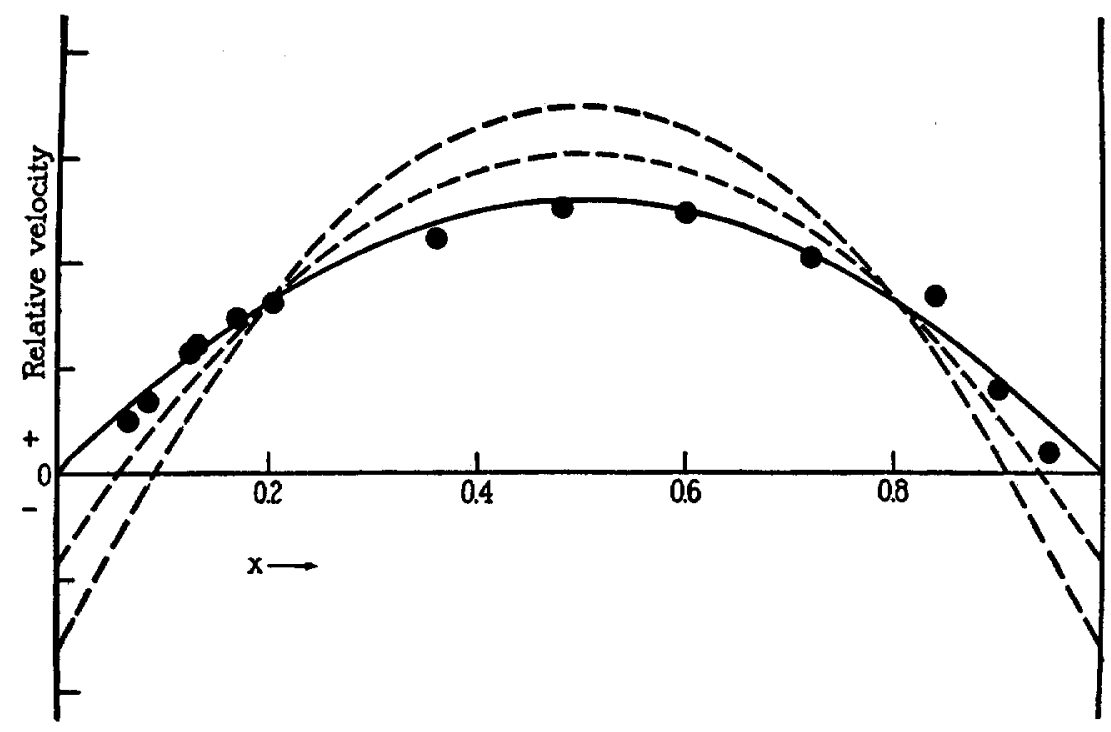

FIG. 3. Experiment with gliadin in 50 per cent ethyl alcohol; otherwise similar to Fig. 1, except that each point is an average of several measurements at the levels indicated. See Table II.

close to the wall, indeed. The interpretation of this behavior is rather difficult. With Henry (12), who states, "It was neither possible nor desirable to make observations right against the wall, but the velocity which should obtain there was deduced by the extrapolation of observations made at various small distances from the wall; ...", we ascribe reversals tentatively to the "wall effects" discussed by Stimson and Jeffrey (13), Lens (14), Bull and Moyer (15), Bikerman (16), and Abramson (17). 


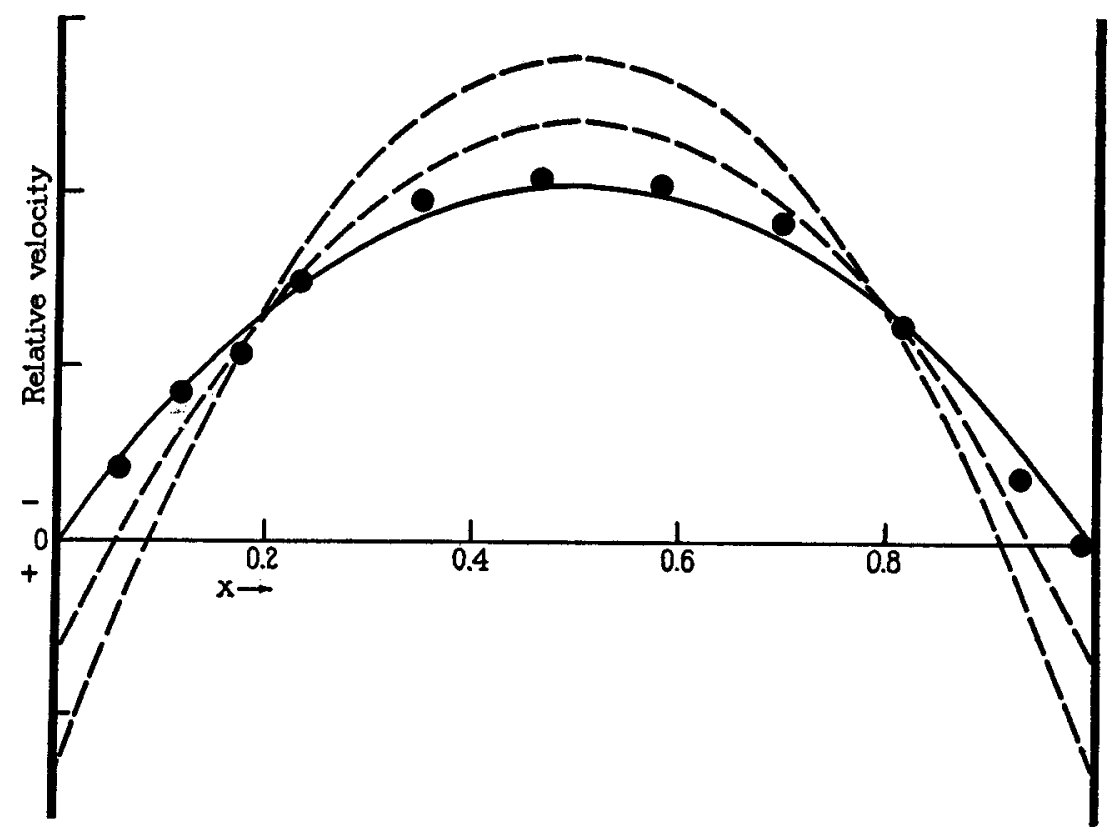

Fic. 4. Experiment with gelatin-coated (Agfa) quartz particles; otherwise similar to Fig. 1, except that each point is an average of several measurements at the levels indicated. See Table II.

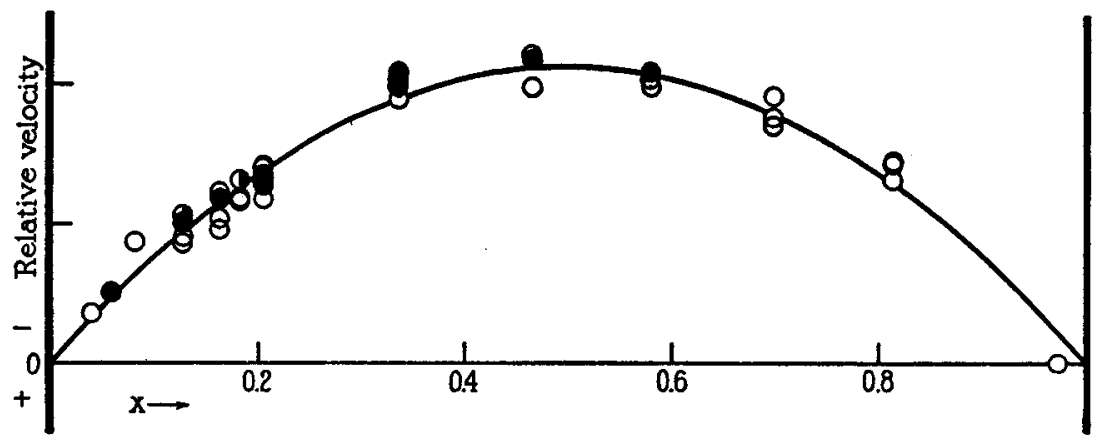

Fig. 5. Experiment with gelatin-coated (Agfa) pyrex glass and parafin oil particles, each point being a single observation. The open circles are glass particles; the closed circles are paraffin oil droplets. The smooth curve has been drawn for $c=0$. The agreement indicates that $R$ is very close to 1.0. See Table II. 


\section{$I I$. Determination of $v$ and $u$ by Linear Extrapolation}

To exclude wall effects and obtain a value of the electric mobility at the wall $(x=0 ; x=1)$, use was made of the fact that equation (1)

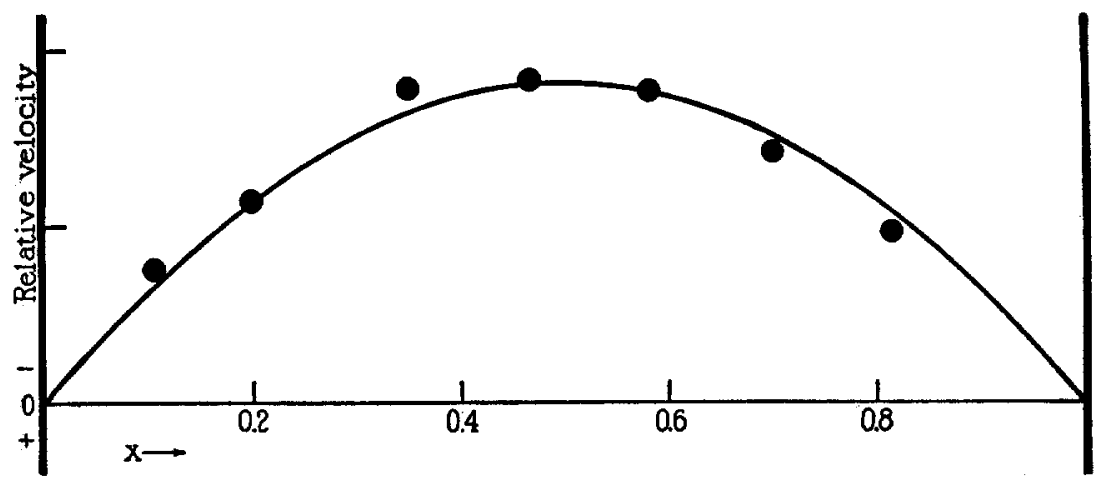

Fig. 6. A control experiment with $\mathrm{M} / 100 \mathrm{KCl}$. The smooth curve has been drawn for $c=0$. Note the similarity between this curve and all the other figures in the paper. See Table II.

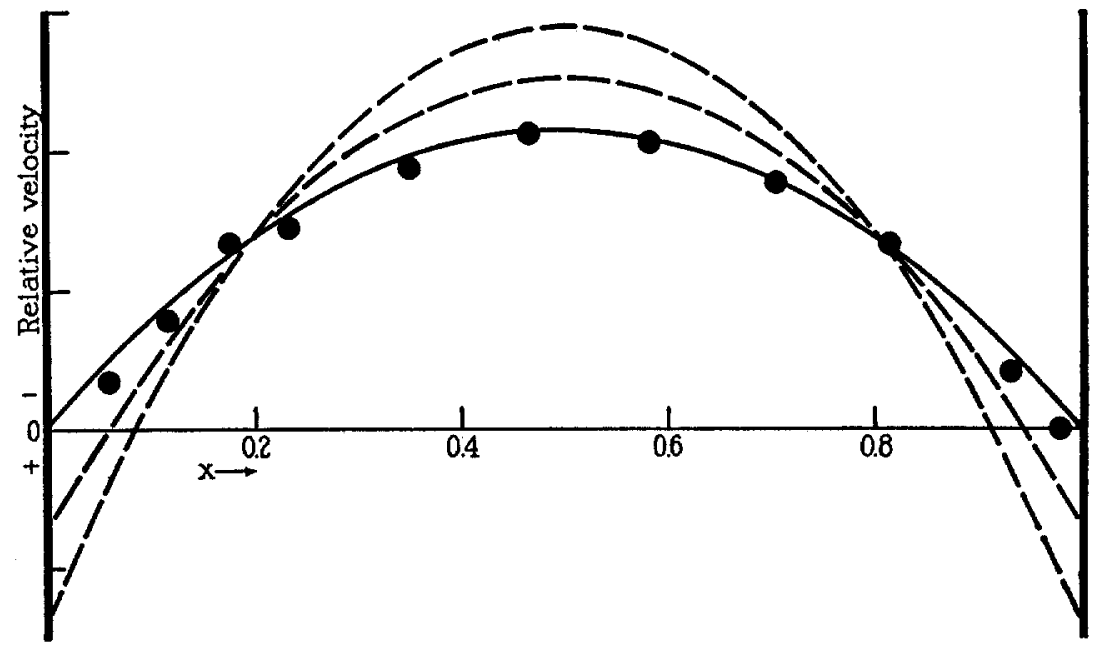

Frg. 7. Similar to Fig. 1 except that Agfa gelatin has been employed and the points represent averaged measurements. See Table II. 
can be employed in a linear form. That is, the observed mobilities, $y$,

$$
y=b\left(x-x^{2}\right)+c,
$$

can be plotted against $\left(x-x^{2}\right)$. The slope of the line is evidently equal to $b$ and its intercept with the ordinate gives $c$. Our data, plotted in this way, could readily be fitted by straight lines. The

TABLE I

Values of $b$ for the different values of $x$, calculated by assuming that $c=0$. Note the constancy of $b$ in each case; this indicates that the intercept is negligible and that $R=1.0$, very nearly.

\begin{tabular}{|c|c|c|c|c|c|c|c|}
\hline \multicolumn{2}{|c|}{ Fig. 1} & \multicolumn{2}{|c|}{ Fig. 2} & \multicolumn{2}{|c|}{ Fig. 4} & \multicolumn{2}{|c|}{ Fig. 6} \\
\hline$x$ & $b$ & $x$ & $b$ & $x$ & $b$ & * & $b$ \\
\hline 0.118 & 0.77 & 0.131 & 0.82 & 0.119 & 0.81 & 0.105 & 0.40 \\
\hline 0.125 & 0.77 & 0.144 & 0.94 & 0.174 & 0.74 & 0.197 & 0.36 \\
\hline 0.141 & 0.84 & 0.186 & 0.90 & 0.233 & 0.83 & 0.348 & 0.40 \\
\hline 0.165 & 0.76 & 0.214 & 0.92 & 0.348 & 0.86 & 0.465 & 0.37 \\
\hline 0.169 & 0.80 & 0.349 & 0.91 & 0.465 & 0.84 & 0.580 & 0.36 \\
\hline 0.177 & 0.78 & 0.465 & 0.93 & 0.581 & 0.84 & 0.698 & 0.34 \\
\hline 0.181 & 0.76 & 0.581 & 0.87 & 0.698 & 0.87 & 0.814 & 0.32 \\
\hline 0.188 & 0.72 & 0.698 & 0.86 & 0.814 & 0.82 & & \\
\hline 0.240 & 0.78 & 0.813 & 0.88 & & & & \\
\hline $\begin{array}{l}0.247 \\
0.271\end{array}$ & $\begin{array}{l}0.83 \\
0.78\end{array}$ & \multicolumn{2}{|c|}{ Fig. 3} & \multicolumn{2}{|c|}{ Fig. 5} & \multicolumn{2}{|c|}{ Fig. 7} \\
\hline 0.294 & 0.73 & $x$ & $b$ & $x$ & $b$ & $x$ & $b$ \\
\hline 0.325 & 0.81 & 0.126 & 0.52 & 0.128 & 0.84 & 0.116 & 1.5 \\
\hline 0.325 & 0.71 & 0.132 & 0.53 & 0.163 & 0.80 & 0.175 & $\begin{array}{l}1.5 \\
1.8\end{array}$ \\
\hline 0.376 & 0.80 & 0.168 & 0.52 & 0.182 & 0.87 & 0.233 & $\begin{array}{l}1.0 \\
1.6\end{array}$ \\
\hline 0.388 & 0.72 & 0.204 & 0.50 & 0.205 & 0.79 & 0.350 & $\begin{array}{l}1.0 \\
1.6\end{array}$ \\
\hline 0.447 & 0.78 & 0.360 & 0.48 & 0.205 & 0.83 & 0.465 & 1.7 \\
\hline 0.518 & 0.78 & 0.480 & 0.51 & 0.336 & 0.88 & 0.582 & 1.7 \\
\hline & & 0.600 & 0.52 & 0.465 & 0.86 & 0.698 & 1.7 \\
\hline & & 0.720 & 0.51 & 0.580 & 0.84 & 0.815 & 1.8 \\
\hline & & 0.840 & 0.56 & 0.697 & 0.86 & & \\
\hline & & & & 0.813 & 0.92 & & \\
\hline
\end{tabular}

straight line giving the best fit, in each case, was extrapolated to $\left(x-x^{2}\right)=0$ in order to obtain $c$. The values of $c$ so obtained furnish a method of testing our value for $R$ independent of the first method. In Table III these values of $c$ are listed; all are very close to the origin or at it. 
TABLE II

Characteristics of the Systems Investigated

\begin{tabular}{|c|c|c|c|c|c|c|}
\hline Fig. & Particle & Flat surface & Adsorbed protein & Medium & $\begin{array}{c}\text { Final pro- } \\
\text { tein concen- } \\
\text { tration }\end{array}$ & $\begin{array}{c}\text { Specific } \\
\text { conductance } \\
\text { of suspen- } \\
\text { sion }\end{array}$ \\
\hline & & & & & per cent & mhos $\times 10^{5}$ \\
\hline 1 & Quartz & $\begin{array}{c}\text { Soft glass } \\
\text { of cell }\end{array}$ & $\begin{array}{l}\text { Gelatin } \\
\quad \text { (Coignet) }\end{array}$ & $\begin{array}{c}\text { Distilled } \\
\text { water }\end{array}$ & 0.2 & 5.1 \\
\hline 2 & Quartz & $\begin{array}{l}\text { Soft glass } \\
\text { of cell }\end{array}$ & $\begin{array}{l}\text { Gelatin } \\
\quad \text { (Coignet) }\end{array}$ & $\begin{array}{c}\text { Distilled } \\
\text { water }\end{array}$ & 0.2 & 5.1 \\
\hline 3 & Quartz & $\begin{array}{c}\text { Soft glass } \\
\text { of cell }\end{array}$ & Gliadin & $\begin{array}{l}50 \text { per cent } \\
\text { ethyl } \\
\text { alcohol }\end{array}$ & 0.2 & 1.6 \\
\hline 4 & Quartz & $\begin{array}{c}\text { Soft glass } \\
\text { of cell }\end{array}$ & $\begin{array}{l}\text { Gelatin } \\
\text { (Agfa) }\end{array}$ & $\begin{array}{c}\text { Distilled } \\
\text { water }\end{array}$ & 0.05 & 2.1 \\
\hline 5 & $\begin{array}{c}\text { Pyrex and } \\
\text { paraffin }\end{array}$ & $\begin{array}{c}\text { Soft glass } \\
\text { of cell }\end{array}$ & $\begin{array}{l}\text { Gelatin } \\
\text { (Agfa) }\end{array}$ & $\begin{array}{c}\text { Distilled } \\
\text { water }\end{array}$ & 0.2 & $9.2^{*}$ \\
\hline 6 & Quartz & $\begin{array}{c}\text { Soft glass } \\
\text { of cell }\end{array}$ & $\begin{array}{l}\text { Gelatin } \\
\text { (Agfa) }\end{array}$ & $0.01 \mathrm{M} \mathrm{KCl}$ & 0.2 & 153 \\
\hline 7 & Quartz & $\begin{array}{c}\text { Soft glass } \\
\text { of cell }\end{array}$ & $\begin{array}{r}\text { Gelatin } \\
\text { (Agfa) }\end{array}$ & $\begin{array}{c}\text { Distilled } \\
\text { water }\end{array}$ & 0.02 & 0.39 \\
\hline
\end{tabular}

* This high conductance is presumably due to the presence of dissolved glass.

TABLE III

The ratio, $R$, of electroosmotic mobility, $u$, to electrophoretic mobility, $v$, in the systems investigated. Values of $c$ have been obtained by a linear extrapolation of the curves of $y$ plotted against $\left(x-x^{2}\right)$. These values of $c$ represent an extrapolated rather than an assumed value. It is of interest to point out that this method of plotting permits the calculation of the mobility of the particles at $x=0$ and $x=1$, with avoidance of the questionable wall effect described in the text. $C, v$, and $u$ are in relative units.

\begin{tabular}{c|c|c|c|c}
\hline \hline Fig. & $c$ & 0 & \multirow{2}{*}{$*$} & $R=\frac{v+c}{v}$ \\
\hline 1 & 0 & 0.123 & -0.123 & 1.00 \\
2 & 0.002 & 0.142 & -0.140 & 0.98 \\
3 & -0.004 & 0.0805 & -0.0845 & 1.05 \\
4 & -0.009 & 0.212 & -0.221 & 1.04 \\
5 & 0 & 0.156 & -0.156 & 1.00 \\
6 & -0.004 & 0.062 & -0.066 & 1.07 \\
7 & -0.031 & 0.289 & -0.320 & 1.11 \\
\hline
\end{tabular}


Having obtained $c$ by means of this method, $R$ can readily be evaluated by means of equation (2). The values of $v$ were obtained at the level $0.2(0.8)$ from the straight lines just described. These lines represent the "stationary levels," according to Komagata (18), for a cell of dimensions corresponding to our cell (6). Values of $R$ thus calculated are also given in Table III. The values of $R$ range from 0.98 to 1.11 and show no tendency for $R$ to increase as the specific conductance decreases. Note that the specific conductances of the suspensions are listed in Table II. The specific conductance here provides more information in regard to electrolyte concentration than "salt added." In dilute solutions, the salt added may contribute less to the ionic strength than that contributed by the salt of the protein solutions, even though dilute.

\section{DISCUSSION}

White, Monaghan, and Urban have explained their results by invoking a "polarization" of the double layer on the particle and claim that electrophoretic measurements in dilute solutions would have to be corrected for this retarding effect to yield true values. In the light of our data, any polarization of the double layer either affects the protein coating of the wall and the particle to an equal extent, or else it retards the particle so slightly that it cannot be detected at present. Since the electroosmosis past a plane protein-coated surface is identical with the electrophoresis of very small particles coated with the same protein, certainly in solutions as dilute as those investigated here (where $\kappa r$ would be small (10)), it follows that these data are consistent with the suggestion previously advanced (10) that the protein molecule "takes its own radius with it" on adsorption and hence keeps $\kappa r$ the same for both the wall and the particle.

\section{SUMMARY}

The ratio of electroosmotic to electrophoretic mobility of certain protein-coated surfaces is very close to 1.0 , even in very dilute solutions of electrolytes.

\section{BIBLIOGRAPHY}

1. Abramson, H. A., J. Gen. Physiol., 1930, 13, 657.

2. Daniel, J., J. Gen. Physiol., 1933, 16, 457. 
3. White, H. L., Monaghan, B., and Urban, F., J. Phys. Chem., 1935, 39, 611. White, H. L., and Monaghan, B., J. Phys. Chem., 1935, 39, 925.

4. Bull, H. B., J. Phys. Chem., 1935, 39, 577.

5. Abramson, H. A., J. Gen. Physiol., 1929, 12, 469.

6. Abramson, H. A., and Grossman, E. B., J. Gen. Physiol., 1931, 14, 563.

7. Abramson, H. A., Electrokinetic phenomena and their application to biology and medicine, New York, The Chemical Catalog Co., Inc., 1934, 78.

8. Moyer, L. S., Biochem. Z., Berlin, 1934, 273, 122. Am. J. Bot., 1934, 21, 293.

9. Abramson, H. A., J. Gen. Physiol., 1929, 13, 169.

10. Abramson, H. A., J. Gen. Physiol., 1932, 15, 575.

11. Kemp, I., and Rideal, E. K., Proc. Roy. Soc. London, Series A, 1934, 147, 11.

12. Henry, D. C., Proc. Roy. Soc. London, Series A, 1931, 133, 106.

13. Stimson, M., and Jeffrey, G. B., Proc. Roy. Soc. London, Series A, 1926, 110, 110.

14. Lens, J., Proc. Roy. Soc. London, Series A, 1933, 139, 596.

15. Bull, H. B., and Moyer, L. S., J. Phys. Chem., 1936, 40, 9.

16. Bikerman, J. J., Z. physik. Chem., Abt. A, 1933, 163, 378.

17. Abramson, H. A., Electrokinetic phenomena and their application to biology and medicine, New York, The Chemical Catalog Co., Inc., 1934, 85.

18. Komagata, S., Researches Electrotechn. Lab., Tokyo, 1933, No. 348, 8. 